\title{
SHORT- AND LONG-TERM OUTCOMES OF A SECOND ARTERIAL CONDUIT FOLLOWING CORONARY BYPASS GRAFTING
}

Sleiman Sebastian Aboul-Hassan ${ }^{1}$, Jakub Marczak ${ }^{1}$, Tomasz Stankowski² ${ }^{2}$, Lukasz Moskal ${ }^{3}$, Maciej Peksa ${ }^{4}$, Marcin Nawotka ${ }^{5}$, Ryszard Stanislawski ${ }^{5}$, Romuald Cichon ${ }^{6}$, and Miroslaw Brykczynski $^{7}$

${ }^{1}$ Heart Diseases Center MEDINET

${ }^{2}$ Sana Heart Center Cottbus

${ }^{3}$ Medinet Heart Center

${ }^{4}$ MEDINET Heart Center Ltd

${ }^{5}$ MEDINET Heart Center Ltd.

${ }^{6}$ Medical University of Warsaw

${ }^{7}$ Lower Silesian Center for Heart Disease MEDINET

August 2, 2021

\begin{abstract}
Background: The aim of this study was to assess the effect on short-term outcomes and long-term survival in patients following coronary artery bypass grafting in whom second arterial conduit(right internal thoracic artery-RITA or radial artery-RA) or saphenous vein was grafted and between RITA and RA as second best arterial conduit. Methods: Between January-2006 and June-2018, 7857-patients met the inclusion criteria and were divided into two groups: single internal thoracic artery: SITA+Vein $\operatorname{group}(n=7140)$ and 2nd-arterial conduit $\operatorname{group}(\mathrm{n}=717)$, of these 537-patients received RITA and 180-patients received RA. Short-term outcomes included: 30-day mortality and Major Adverse Cardiac and Cerebral Events(MACCE), reoperation for bleeding and deep sternal wound infection(DSWI). The long-term outcome was all-cause mortality. propensity score(PS) matching was used to match patients between the groups. Results: Before as well as after PS-matching, no significant differences were observed between 2nd-arterial conduit vs SITA+Vein groups and between RITA vs RA groups in terms of 30-day mortality, 30-day MACCE, reoperation for bleeding and incidence of DSWI. The use of 2nd-arterial conduit was associated with a significant reduction in long-term mortality before(HR:0.52;95\%CI;0.43-0.64;p $<0.001)$ as well as after PSmatching(HR:0.77;95\%CI;0.60-0.99; $=0.04)$. RA and RITA as second arterial conduit had comparable long-term mortality before(HR:1.22;95\%CI;0.82-1.82;p=0.3) as well as after PS-matching(HR:0.96;95\%CI;0.58-1.58; $\mathrm{p}=0.87)$. Conclusions: The use of 2nd-arterial conduit vs vein is associated with improved long-term survival. As for the 2nd-best arterial conduit, RA and RITA had comparable long-term mortality.
\end{abstract}

\section{INTRODUCTION}

The use of left internal thoracic artery(LITA) in grafting of the left anterior descending artery(LAD) provides undisputable advantage in patient undergoing coronary artery bypass grafting $(\mathrm{CABG})^{1-3}$. Tremendous success of the LITA graft encouraged use of the other arterial conduits such as right internal thoracic(RITA) or radial artery(RA). The concept of full arterial revascularization in grafting of the non-LAD vessels was coined in an attempt to further improve survival in patients following multivessel CABG. Several observational studies as well as meta-analyses reported a survival benefit with RITA or RA used as a second 
arterial graft $^{4-8}$. Yet, the adoption of multiple arterial grafting remains unsatisfactory ranging between $4 \%$ to $32 \%^{5,9-10}$. Despite the reported benefit of the full arterial grafting, the Arterial Revascularization Trial(ART) found no survival benefit in the intention-to-treat analysis at 5-and 10-years outcomes between bilateral(BITA) and single internal thoracic arteries. However the high cross-over rate and the use of RA could have introduced a systemic error to the results ${ }^{11}$.

Equivocal long-term results of the randomized trial in addition to reported increased risk of sternal wound infection in patients with BITA ${ }^{12}$ as well as technical complexity associated with using multiple arterial grafts led to inconclusive results on whether the use of second arterial graft is safe and associated with improved short- and long-term outcomes. The aim of this study was to assess the effect on short-term outcomes and long-term survival in patients following CABG between second arterial conduit(RITA or RA) and saphenous vein and between RITA and RA as second best arterial conduit.

\section{MATERIALS AND METHODS}

\section{Study design}

This observational, retrospective study was designed according to STROBE guidelines(Strengthening The Reporting of Observational Studies in Epidemiology) ${ }^{13}$. Between January-2006 and June-2018, 9602-patients underwent isolated CABG at two cardiac surgery centers(Medinet Heart Center Ltd in Nowa Sol and Wroclaw, Poland). We retrospectively analyzed prospectively collected data from the surgical database in both centers. The data are collected and reported in accordance with Polish National Registry of Cardiac Surgery Procedures database which is mandatory for every cardiac surgery department in Poland. The database captures detailed information on preoperative, intraoperative, and hospital postoperative variables for all patients undergoing any cardiac surgery procedure.

Patients included in the final analysis met the following criteria: first-time isolated CABG with multivessel disease requiring at least two coronary grafts; LITA used in situ to graft LAD territory and additional saphenous vein graft(SVG) for non-LAD target(SITA+Vein group) or one of the ITA's used in-situ to graft LAD territory and additional second ITA in-situ or as composite graft for non-LAD target or the use of RA as second graft for the non-LAD target $\left(2^{\text {nd }}\right.$-arterial conduit group). Patients with additional SVG in the $2^{\text {nd }}$ arterial conduit group were also included. ITA's were harvested as pedicled or skeletonized graft, whereas RA was harvested as pedicled graft. RITA was used in cases where target stenosis was $(>70 \%)$ or in isolated Left main disease $(>50 \%)$. RITA was used as an in-situ graft or as a composite graft proximally connected to LITA. The RA was used in cases where target stenosis was $(>70 \%)$ in the left coronary system or $(>80 \%)$ in the right coronary system. RA was used as a free graft directly connected to the ascending aorta. Overall, 7857-patients met the inclusion criteria and were divided into two groups: SITA+Vein $\operatorname{group}(\mathrm{n}=7140)$ and $2^{\text {nd }}$-arterial conduit group $(\mathrm{n}=717)$, of these 537 -patients received RITA and 180-patients received RA. Figure.1 represents patients flow chart diagram. The study was approved by the Institutional Review Board at Medinet Heart Center. An individual consent of the patients for anonymous data analysis was waived by the Committee.

\section{Study Endpoints and definitions}

Short-term outcomes included: 30-day mortality, 30-day Major Adverse Cardiac and Cerebral Events(MACCE), reoperation for bleeding and deep sternal wound infection(DSWI). MACCE was defined as composite of mortality, myocardial infarction and stroke. MI was defined according to the fourth international definition of $\mathrm{MI}^{14}$. Stroke was defined as the development of a new permanent neurologic deficit as confirmed by stroke team member assessment of the patient and computed tomography of the central nervous system, magnetic resonance imaging, or at autopsy examination. DSWI was defined by the Center for Disease Control and Prevention ${ }^{15}$. Incomplete revascularization(IR) was defined according to anatomic definition where at least one vessel with a $\operatorname{stenosis}(>50 \%)$ and a size of $>1.5 \mathrm{~mm}$ was not revascularized ${ }^{16}$.

The long-term outcome was all-cause mortality, which is considered as an objective and unbiased endpoint for comparative studies ${ }^{17}$. Information about death at follow-up was retrieved from the National Health 
Care registry of the Ministry of Health of the Republic of Poland, that stores and analyses all health-related data. Data regarding postoperative outcomes were available for all patients in the study.

\section{Statistical analysis}

Statistical analyses were performed using statistical software STATISTICA(TIBCO Software Inc.2017, version-13.Palo Alto-USA). Continuous variables were expressed as means $\pm S D$, while categorical variables as numbers and percentages. For continuous data Student's t-test was used for in between groups comparisons, while categorical variables were compared with Pearson- $\chi 2$-test. Cox regression models were used to find the univariable and multivariable predictors of late all-cause mortality. Multivariable model for the whole cohort was built using preoperative variables presented in Table- 1 in addition to type of surgery: On-pump-CABG(ONCAB) or off-pump-CABG(OPCAB) and completeness of revascularization. The multivariable model considered all univariate significant variables $(p<0.1)$ with using the stepwise method(backward and forward methods resulted in the same model).

To further confirm the results and to reduce the risk of selection bias inherent to a retrospective, observational studies, a propensity score(PS) matching was used to match patients between the groups(SITA+Vein group vs $2^{\text {nd }}$-arterial group)and(RITA group vs RA group). Propensity scores were generated from a multivariable logistic regression model based on 18-preoperative variables as mentioned in Table-1. Patients were then matched in 1:1 fashion using a caliper matching method without replacement with a caliper width of 0.2standard deviation of the logit of the $\mathrm{PS}^{18-20}$. The balance of the covariates was tested using standardized mean difference(SMD). Statistical guidelines suggest a meaningful covariate balance of the variables used to generate the PS between the two groups to be between -0.1[?]SMD[?] $0.1^{18}$. Matched data were analyzed using procedures for matched analyses. McNemar's test was used for binary outcomes.

Survival in the unadjusted and PS adjusted populations were estimated using the Kaplan-Meier method and were expressed as percentages. Log-rank test was used to compare the data. Statistical significance was defined as $p$-value of $<0.05$.

\section{RESULTS}

\section{SITA+Vein vs $2^{\text {nd }}$-arterial conduit}

Baseline characteristics of patients in the unmatched and matched cohort are presented in Table-1. In the unmatched cohort, patients in the SITA+Vein group presented higher prevalence of comorbidities. In particular they were more likely to be older, female and to have peripheral vascular disease, diabetes, history of cerebrovascular adverse events, recent myocardial infarction, impaired left ventricular function, moderate and severe renal impairment. Whereas patients in the $2^{\text {nd }}$ arterial conduit group were more likely to be active smokers and emergent or urgent cases and to have history of percutaneous coronary interventions, hyperlipidemia and left main disease. After PS-matching, both groups were comparable for all baseline characteristics(Table-1). PS-matching selected 695-pairs and both groups were found to be well balanced.

The mean number of grafts performed in the SITA+Vein group was higher than in the $2^{\text {nd }}$-arterial conduit group before $(\mathrm{p}<0.001)$ as well as after PS-matching $(\mathrm{p}<0.001)$. In the unmatched, no difference was observed between both groups in terms of OPCAB vs ONCAB or prevalence of IR. However, after matching, $2^{\text {nd }}$ arterial conduit group had higher rate of $\operatorname{OPCAB}(46.9 \%$ vs $36.9 \%$ in the SITA+Vein group;p $<0.001)$ and higher rate of $\operatorname{IR}(25.8 \%$ vs $20.0 \%$ in the SITA+Vein group; $\mathrm{p}=0.008)$ (Table-1).

Before as well as after PS-matching, no significant differences were observed between both groups in terms of 30-day mortality, 30-day MACCE, reoperation for bleeding and incidence of DSWI(Table-2).

In the unmatched cohort, mean follow-up was 7.2 \pm 3.66 -years. Survival at-5,-10 and 14-years were $92.6 \%$ vs $85.6 \%, 80.2 \%$ vs $68.1 \%$ and $73.2 \%$ vs $54.8 \%$ in the $2^{\text {nd }}$ arterial conduit group vs SITA+Vein group, respectively(Log-rank $\mathrm{p}<0.001)($ Figure. $2 \mathrm{~A})$. In the matched cohort, mean follow-up was $7.74 \pm 3.79$-years. Survival at- $5,-10$ and 14 -years were $92.6 \%$ vs $89.7 \%, 79.9 \%$ vs $78.3 \%$ and $72.4 \%$ vs $61.1 \%$ in the $2^{\text {nd }}$ arterial conduit group vs SITA+Vein group, respectively $(\log$-rank $\mathrm{p}=0.04)$ (Figure.2B). The use of $2^{\text {nd }}$-arterial graft 
was associated with a significant reduction in long-term mortality before(HR:0.52;95\%CI;0.43-0.64;p<0.001) as well as after PS-matching(HR:0.77;95\%CI;0.60-0.99;p=0.04).

Cox regression models were used to find the univariable and multivariable predictors of late all-cause mortality. Multivariable analysis identified the presence of $2^{\text {nd }}$-arterial conduit as a significant predictor of improved survival(HR:0.67;95\% CI;0.55-0.82;p<0.001). Other significant predictors for increased late mortality were age $>70$, NYHA III-IV, smoking, diabetes, severe renal impairment, peripheral vascular disease, history of cerebrovascular adverse events, chronic lung disease, left main disease, IR, impaired LV function and urgent/emergent cases(Table-3).

\section{RITA VS RA as second arterial conduit}

Baseline characteristics of patients in the unmatched and matched cohort are presented in Table-4. In the unmatched cohort, patients in the RA group were more likely to be female and obese and to have diabetes, hyperlipidemia and moderate renal impairment. Whereas patients in the RITA group were more likely to be operated on as an emergency or urgent cases and to have arterial hypertension and left main stem disease. After PS-matching, both groups were comparable for all baseline characteristics(Table-4). PS-matching selected 174-pairs and both groups showed good degree of balance.

The mean number of grafts performed and the rate of OPCAB in the RITA group was higher than in the RA group before as well as after PS matching. In the unmatched cohort, the prevalence of IR in the RA group was higher than in RITA group $(33.8 \%$ vs $22.7 \%, \mathrm{p}=0.0029)$. However after matching, no difference in terms of incomplete revascularization was observed between both groups(Table-4).

Before as well as after PS-matching, no significant differences were observed between both groups in terms of 30-day mortality, 30-day MACCE, reoperation for bleeding and incidence of DSWI(Table-5).

In the unmatched cohort, survival at-5,-10 and 14 -years were $92.6 \%$ vs $93.0 \%, 82.2 \%$ vs $77.4 \%$ and $75.4 \%$ vs $70.8 \%$ in the RITA group vs RA group, respectively(Log-rank $\mathrm{p}=0.27)$ (Figure.3A). In the matched cohort, Survival at 5, 10 and 14-years were $93.2 \%$ vs $93.3 \%, 77.7 \%$ vs $77.8 \%$ and $69.6 \%$ vs $72.0 \%$ in the RITA group vs RA group, respectively(Log-rank $\mathrm{p}=0.88)$ (Figure.3B). RA and RITA as second arterial conduit had comparable long-term mortality before(HR:1.22;95\% CI;0.82-1.82; $=0.3$ ) as well as after PSmatching(HR:0.96;95\% CI;0.58-1.58;p=0.87).

Multivariable analysis identified Age $>70$, diabetes, severe renal impairment, PVD and impaired LV function as independent predictors of late mortality in patients with $2^{\text {nd }}$-arterial conduit(Table-3).

\section{DISCUSSION}

The present study indicated that the use of $2^{\text {nd }}$-arterial conduit might be associated with superior long-term survival in patients following CABG. On the other hand, RA when compared to RITA as a $2^{\text {nd }}$ arterial conduit had a similar long-term outcome.

The use of multiple arterial grafts has been extensively studied over the past decade. Several observational studies as well as meta-analyses reported a survival benefit when RITA or RA is used as second arterial graft $^{4-8}$. Yet, the adoption rate of multiple arterial grafting ranges between $4 \%$ to $32 \%^{5,9-10}$. Despite the reported benefit of the arterial grafts, ART found no survival benefit in the intention-to-treat analysis at 10-years between BITA and SITA ${ }^{11}$. Parasca et al. in a study from the SYNTAX trial and registry found no survival benefit at 5 -years follow-up in patients with second arterial vs venous graft ${ }^{10}$. However, Chikwe and colleagues in a 3588-propensity matched multi-arterial and single-arterial CABG study, reported that multiple arterial CABG was associated with reduced long-term mortality as well as MI and reintervention rate $^{21}$ on the other hand, controversy still remain on whether RA has similar long-term benefits as RITA. Schwan et al. in a multicenter study reported equally improved long-term survival when RITA or RA was used $^{22}$. Whereas Shi et al. ${ }^{23}$ and Benedetto et al. ${ }^{24}$ reported significant survival benefit from RITA when compared to RA. On the contrary, the recent results of the 10 -years RAPCO trials ${ }^{25}$, showed that the 10 year patency rate of the RA is significantly higher than that of the free RITA and better than that of the 
vein graft, whereas long-term survival was improved when RA was compared to free RITA but not when RA was compared to vein graft. It should be noted that in the RAPCO trial, RITA was used as free graft directly connected to the aorta and the possible caliber mismatch between them could affect and reduce the patency of the RITA graft. Therefore, this uncertain and controversial long-term results in addition to increased risk of DSWI and the perceived technical complexity when using multiple arterial grafts lead to inconclusive results on whether the use of second arterial graft is safe and associated with improved shortand long-term outcomes.

By conducting our PS-matched study based on 695-pairs of patients receiving $2^{\text {nd }}$-arterial graft vs SITA+Vein we found that the use of the $2^{\text {nd }}$-arterial graft is associated with improved survival. On the other hand RA and RITA as second arterial conduit had comparable long-term mortality before as well as after PS matching. Recent meta-analysis performed by Gaudino et al. supported our findings. However, they also showed that the use of RITA was associated with increased risk of DSWI but not when RA was used ${ }^{8,11}$. In our study there was no difference between $2^{\text {nd }}$-arterial graft vs SITA+Vein in terms of DSWI nor it was between RITA and RA. This was probably due to the fact that approximately $70 \%(67.6 \%)$ of the patients in the $2^{\text {nd }}$ arterial graft group had skeletonized ITA's and it was showed in the sub study of ART as well as in the recent meta-analysis, that with a skeletonization technique, the risk of sternal wound complication with BITA is similar to that after standard pedicled SITA harvesting ${ }^{8,26}$.

On the other hand, IR following patients undergoing CABG is not a rare phenomenon and is associated with increased long-term mortality as reported by Garcia et al. ${ }^{27}$. In the present study we analyzed multivariable predictors of late all-cause mortality in the $2^{\text {nd }}$-arterial conduit group vs SITA+Vein and in the $2^{\text {nd }}$-arterial conduit group(RA vs RITA). In the whole cohort, IR was a significant independent predictor of late mortality(HR:1.25;95\% CI;1.13-1.39;p<0.001). However, this was not the case in the subgroup of $2^{\text {nd }}$-arterial graft (RITA vs RA)(HR:1.46;95\% CI;0.96-2.24; $=0.07$ ). Therefore IR in patients with multiple arterial grafts may not have a negative impact on long-term survival in patients following CABG.

The present study has several limitations. The main limitation is the lack of randomization. In order to limit inherent risks of potential selection bias a propensity score matching procedure was performed. Secondly, no data were available with respect to cause of death, need for repeated revascularization or graft patency. Thirdly, the power of the study to detect differences in survival among RITA and RA is very small, because of the small sample size. Finally, due to small number of patients in the RA group we did not analyze outcomes of different conduits with respect to the grafted territory.

\section{CONCLUSION}

The present study shows that the use of $2^{\text {nd }}$-arterial conduit vs vein is associated with improved long-term survival. As for the $2^{\text {nd }}$-best arterial conduit, RA and RITA had comparable long-term mortality.

Conflict of interest: none declared

\section{Figure Legends:}

Figure.1:STROBE flow diagram.

Figure.2:Kaplan-Meier survival curve probabilities in the $2^{\text {nd }}$-arterial conduit and SITA+Vein groups. Abefore PSM. B-after PSM.

Figure.3:Kaplan-Meier survival curve probabilities in the RITA and the RA groups. A-before PSM. B-after PSM.

Table-1.Baseline and operative characteristics $\left(2^{\text {nd }}\right.$-arterial conduit vs SITA+Vein $)$

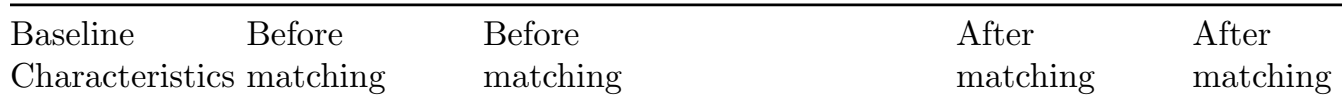




\begin{tabular}{|c|c|c|c|c|c|c|c|}
\hline & $\begin{array}{l}2^{\text {nd }} \text {-arterial } \\
\text { conduit } \\
(\mathrm{n}=717)\end{array}$ & $\begin{array}{l}\text { SITA+Vein } \\
(\mathrm{n}=7140)\end{array}$ & $\mathrm{p}$ & $\begin{array}{l}2^{\text {nd }} \text {-arterial } \\
\text { conduit } \\
(\mathrm{n}=695)\end{array}$ & $\begin{array}{l}\text { SITA+Vein } \\
(\mathrm{n}=695)\end{array}$ & $\mathrm{p}$ & SMD \\
\hline $\operatorname{Age}(y)$ & $57.9 \pm 8.54$ & $65 \pm 8.42$ & $<0.001$ & $58.4 \pm 8.17$ & $58.3 \pm 8.54$ & 0.88 & 0.01 \\
\hline Age $>70$ & $54(7.5)$ & $2071(29.0)$ & $<0.001$ & $54(7.7)$ & $68(9.7)$ & 0.18 & \\
\hline $\begin{array}{l}\text { Female } \\
\text { gender }\end{array}$ & $126(17.5)$ & $1875(26.2)$ & $<0.001$ & $125(17.9)$ & $133(19.1)$ & 0.58 & -0.04 \\
\hline PVD & $86(11.9)$ & $1189(16.6)$ & 0.001 & $86(12.3)$ & $97(13.9)$ & 0.38 & -0.07 \\
\hline $\operatorname{BMI}\left(\mathrm{kg} / \mathrm{m}^{2}\right)$ & $28.2 \pm 3.9$ & $28.5 \pm 6.8$ & 0.22 & $28.2 \pm 3.94$ & $28.3 \pm 4.32$ & 0.58 & -0.02 \\
\hline BMI[?]30 & $220(30.6)$ & $2400(33.6)$ & 0.11 & $215(30.9)$ & $236(33.9)$ & 0.22 & \\
\hline $\begin{array}{l}\text { History of } \\
\text { CAEs }\end{array}$ & $14(1.95)$ & $333(4.6)$ & $<0.001$ & $14(2.0)$ & $12(1.7)$ & 0.69 & 0.086 \\
\hline Diabetes & $159(22.1)$ & $2665(37.3)$ & $<0.001$ & $157(22.5)$ & $167(24.0)$ & 0.52 & -0.04 \\
\hline $\begin{array}{l}\mathrm{MI}(<90 \\
\text { days })\end{array}$ & $193(26.9)$ & $2489(34.8)$ & $<0.001$ & $189(27.1)$ & $174(25.0)$ & 0.35 & 0.06 \\
\hline $\begin{array}{l}\text { NYHA } \\
\text { III-IV }\end{array}$ & $55(7.6)$ & $458(6.41)$ & 0.19 & $53(7.6)$ & $61(8.7)$ & 0.43 & -0.08 \\
\hline CLD & $36(5.0)$ & $437(6.12)$ & 0.23 & $36(5.1)$ & $36(5.1)$ & $>0.99$ & 0.000 \\
\hline PCI & $194(27.0)$ & $1623(22.7)$ & 0.008 & $183(26.3)$ & $188(27.0)$ & 0.76 & -0.02 \\
\hline $\begin{array}{l}\text { Active } \\
\text { smokers }\end{array}$ & $197(27.4)$ & $1434(20.0)$ & $<0.001$ & $191(27.4)$ & $169(24.3)$ & 0.17 & 0.09 \\
\hline Hypertension & $620(86.4)$ & $6043(84.6)$ & 0.19 & $599(86.1)$ & $601(86.4)$ & 0.87 & -0.01 \\
\hline Hyperlipidemia & $310(43.2)$ & $2640(36.9)$ & 0.001 & $295(42.4)$ & $279(40.1)$ & 0.38 & 0.05 \\
\hline $\begin{array}{l}\text { Moderate } \\
\text { renal } \\
\text { impairment }\end{array}$ & $397(55.3)$ & $4273(59.8)$ & 0.02 & $389(55.9)$ & $372(53.5)$ & 0.35 & 0.05 \\
\hline $\begin{array}{l}\text { Severe } \\
\text { renal } \\
\text { impairment }\end{array}$ & $32(4.46)$ & $889(12.4)$ & $<0.001$ & $32(4.6)$ & $38(5.4)$ & 0.46 & -0.099 \\
\hline $\mathrm{EF}<50 \%$ & $171(23.8)$ & $2295(32.1)$ & $<0.001$ & $169(24.3)$ & $167(24.0)$ & 0.9 & 0.008 \\
\hline LM & 301(41.9) & $2166(30.3)$ & $<0.001$ & $288(41.4)$ & $282(40.5)$ & 0.74 & 0.01 \\
\hline Emergent/Urge & e日e8(41.5) & $2611(36.5)$ & 0.008 & $285(41.0)$ & $287(41.2)$ & 0.91 & -0.006 \\
\hline $\begin{array}{l}\text { Operative } \\
\text { Characteristics }\end{array}$ & & & & & & & \\
\hline OPCAB & $330(46.0)$ & $3095(43.3)$ & 0.16 & $326(46.9)$ & $257(36.9)$ & $<0.001$ & \\
\hline $\begin{array}{l}\text { Number of } \\
\text { grafts }\end{array}$ & $2.4 \pm 0.59$ & $2.7 \pm 0.66$ & $<0.001$ & $2.4 \pm 0.58$ & $2.7 \pm 0.68$ & $<0.001$ & \\
\hline $\begin{array}{l}\text { Incomplete } \\
\text { revascularizati }\end{array}$ & $183(25.5)$ & $1713(23.9)$ & 0.36 & $180(25.8)$ & $139(20.0)$ & 0.008 & \\
\hline
\end{tabular}

Data are expressed as mean $\pm \mathrm{SD}$ or $\mathrm{n}(\%)$. Moderate and severe renal impairment defined as $\quad$ eGFR $>50<85 \mathrm{ml} / \mathrm{min} / 1.73 \mathrm{~m}^{2}$ and $\quad \mathrm{eGFR}<50 \mathrm{ml} / \mathrm{min} / 1.73 \mathrm{~m}^{2}$, respectively. BMI=Body mass index $; \mathrm{CAE}=$ Cerebral adverse events; $\mathrm{CLD}=$ Chronic lung disease; $\mathrm{LM}=$ Left main disease;EF $=$ Ejection fraction; $\mathrm{MI}=$ Myocardial Infarction;NYHA=New York Heart Association;OPCAB=Off-pump coronary artery bypass grafting; $\mathrm{PCI}=$ Percutaneous coronary intervention; $\mathrm{PVD}=$ Peripheral vascular disease.

Table-2.Postoperative outcomes $\left(2^{\text {nd- }}\right.$ arterial conduit vs SITA+Vein $)$

$\begin{array}{llllll}\text { Before } & \text { Before } & \text { Before } & \text { After } & \text { After } & \text { After } \\ \text { matching } & \text { matching } & \text { matching } & \text { matching } & \text { matching } & \text { matching }\end{array}$




\begin{tabular}{|c|c|c|c|c|c|c|}
\hline & $\begin{array}{l}2^{\text {nd- }} \text { arterial } \\
\text { conduit } \\
(\mathrm{n}=717)\end{array}$ & $\begin{array}{l}\text { SITA+Vein } \\
(\mathrm{n}=7140)\end{array}$ & $\mathrm{P}^{\mathrm{a}}$ & $\begin{array}{l}2^{\text {nd- }} \text { arterial } \\
\text { conduit } \\
(\mathrm{n}=695)\end{array}$ & $\begin{array}{l}\text { SITA+Vein } \\
(\mathrm{n}=695)\end{array}$ & $\mathrm{P}^{\mathrm{b}}$ \\
\hline $\begin{array}{l}\text { 30-day } \\
\text { mortality }\end{array}$ & $9(1.2)$ & $137(1.9)$ & 0.20 & $9(1.2)$ & $2(0.2)$ & 0.07 \\
\hline $\begin{array}{l}\text { 30-day } \\
\text { MACCE }\end{array}$ & $30(4.1)$ & $315(4.4)$ & 0.64 & $28(4.0)$ & $19(2.7)$ & 0.24 \\
\hline $\begin{array}{l}\text { Rethoracotomy } \\
\text { due to } \\
\text { bleeding }\end{array}$ & $41(5.7)$ & $335(4.6)$ & 0.21 & $40(5.7)$ & $37(5.3)$ & 0.81 \\
\hline DSWI & $23(3.2)$ & $213(2.9)$ & 0.73 & $23(3.3)$ & $24(3.4)$ & $>0.99$ \\
\hline
\end{tabular}

Data are expressed as n(\%). a-Chi-square test;b-McNemar test. DSWI=Deep sternal wound infection;MACCE $=$ Major advers cardiac and cerebral events.

Table-3.Multivariable predictors of late all-cause mortality

\begin{tabular}{|c|c|c|}
\hline & $\begin{array}{l}2^{\text {nd }} \text {-arterial conduit group vs SITA+Vein } \\
\text { HR }(95 \% \text { CI })\end{array}$ & $\begin{array}{l}2^{\text {nd }} \text {-arterial conduit group vs SITA+Vein } \\
\text { p }\end{array}$ \\
\hline 2nd arterial conduit & $0.67(0.55-0.82)$ & $<0.001$ \\
\hline Age $>70 y$ & $1.82(1.66-2.01)$ & $<0.001$ \\
\hline Female gender & $0.83(0.75-0.02)$ & $<0.001$ \\
\hline NYHA III-IV & $1.6(1.39-1.85)$ & $<0.001$ \\
\hline Active smoker & $1.19(1.05-1.35)$ & 0.004 \\
\hline Diabetes & $1.31(1.20-1.44)$ & $<0.001$ \\
\hline Severe renal impairment & $1.7(1.52-1.91)$ & $<0.001$ \\
\hline PVD & $1.58(1.42-1.76)$ & $<0.001$ \\
\hline History of CAEs & $1.27(1.06-1.52)$ & 0.008 \\
\hline CLD & $1.91(1.65-2.21)$ & $<0.001$ \\
\hline LM & $1.1(1.00-1.21)$ & 0.04 \\
\hline Incomplete revascularization & $1.25(1.13-1.39)$ & $<0.001$ \\
\hline $\mathrm{EF}<50 \%$ & $1.71(1.56-1.88)$ & $<0.001$ \\
\hline Emergent/Urgent & $1.11(1.01-1.22)$ & 0.02 \\
\hline
\end{tabular}

Severe renal impairment defined as eGFR $<50 \mathrm{ml} / \mathrm{min} / 1.73 \mathrm{~m}^{2}$. CAEs $=$ Cerebral adverse events; $\mathrm{CLD}=$ Chronic lung disease;HR $=$ Hazard ratio;LM=Left main disease;EF=Ejection fraction; $\mathrm{PVD}=$ Peripheral vascular disease;NYHA=New York Heart Association

Table-4.Baseline and operative characteristics(RIMA vs RA as $2^{\text {nd }}$-arterial conduit)

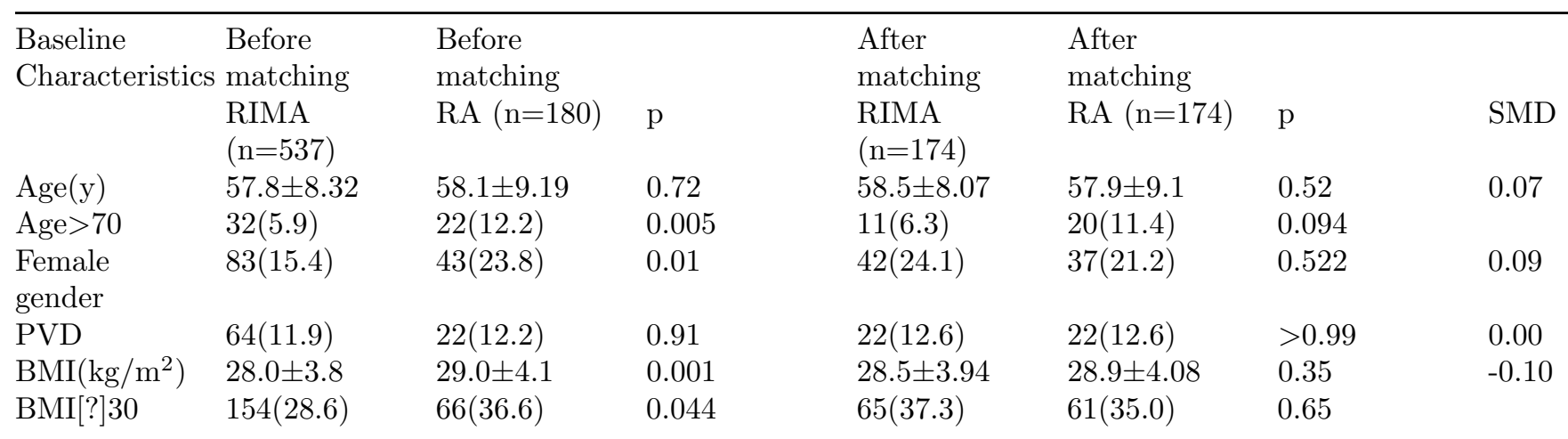




\begin{tabular}{|c|c|c|c|c|c|c|c|}
\hline $\begin{array}{l}\text { History of } \\
\text { CAEs }\end{array}$ & $9(1.67)$ & $5(2.7)$ & 0.35 & $4(2.29)$ & $4(2.29)$ & $>0.99$ & 0.00 \\
\hline Diabetes & $110(20.4)$ & $49(27.2)$ & 0.059 & $42(24.1)$ & $44(25.2)$ & 0.80 & -0.03 \\
\hline $\begin{array}{l}\mathrm{MI}(<90 \\
\text { days })\end{array}$ & $147(27.3)$ & $46(25.5)$ & 0.63 & $49(6.8)$ & $44(25.2)$ & 0.54 & 0.08 \\
\hline $\begin{array}{l}\text { NYHA } \\
\text { III-IV }\end{array}$ & $37(6.8)$ & $18(10)$ & 0.17 & $14(8.0)$ & $16(9.1)$ & 0.7 & -0.08 \\
\hline CLD & $29(5.4)$ & $7(3.8)$ & 0.42 & $6(3.4)$ & $7(4.0)$ & 0.77 & -0.08 \\
\hline PCI & $141(26.2)$ & $53(29.4)$ & 0.4 & $56(32.1)$ & $52(29.8)$ & 0.64 & 0.05 \\
\hline $\begin{array}{l}\text { Active } \\
\text { smokers }\end{array}$ & $148(27.5)$ & $49(27.2)$ & 0.92 & $47(27.0)$ & $47(27.0)$ & $>0.99$ & 0.00 \\
\hline Hypertension & $472(87.8)$ & $148(82.2)$ & 0.054 & $145(83.3)$ & $144(82.7)$ & 0.88 & 0.02 \\
\hline Hyperlipidemia 2 & $220(40.9)$ & $90(50)$ & 0.034 & $80(45.9)$ & $85(48.8)$ & 0.59 & -0.06 \\
\hline $\begin{array}{l}\text { Moderate } \\
\text { renal } \\
\text { impairment }\end{array}$ & $283(52.7)$ & $114(63.3)$ & 0.013 & $102(58.6)$ & $109(62.6)$ & 0.44 & -0.09 \\
\hline $\begin{array}{l}\text { Severe } \\
\text { renal } \\
\text { impairment }\end{array}$ & $24(4.4)$ & $8(4.4)$ & 0.98 & $7(4.0)$ & $8(4.5)$ & 0.79 & -0.07 \\
\hline $\mathrm{EF}<50 \%$ & $125(23.2)$ & $46(25.5)$ & 0.53 & $39(22.4)$ & $44(25.2)$ & 0.52 & -0.08 \\
\hline LM & $244(45.4)$ & $57(31.6)$ & 0.001 & $50(28.7)$ & $57(32.7)$ & 0.41 & 0.10 \\
\hline $\begin{array}{l}\text { Emergent/Urge } \\
\text { Operative }\end{array}$ & e日t3(45.2) & $55(30.5)$ & $<0.001$ & $50(28.7)$ & $55(31.6)$ & 0.55 & -0.07 \\
\hline Characteristics & & & & & & & \\
\hline OPCAB & $276(51.3)$ & $54(30)$ & $<0.001$ & $82(47.1)$ & $53(30.4)$ & 0.001 & \\
\hline $\begin{array}{l}\text { Number of } \\
\text { grafts }\end{array}$ & $2.48 \pm 0.61$ & $2.22 \pm 0.45$ & $<0.001$ & $2.4 \pm 0.59$ & $2.21 \pm 0.46$ & $<0.001$ & \\
\hline Incomplete & $122(22.7)$ & $61(33.8)$ & 0.0029 & $46(26.4)$ & $59(33.9)$ & 0.12 & \\
\hline
\end{tabular}

Data are expressed as mean $\pm \mathrm{SD}$ or $\mathrm{n}(\%)$. Moderate and severe renal impairment defined as $\quad$ eGFR $>50<85 \mathrm{ml} / \mathrm{min} / 1.73 \mathrm{~m}^{2}$ and $\mathrm{eGFR}<50 \mathrm{ml} / \mathrm{min} / 1.73 \mathrm{~m}^{2}$, respectively. BMI=Body mass index; $\mathrm{CAE}=$ Cerebral adverse events; $\mathrm{CLD}=$ Chronic lung disease;LM=Left main disease;EF=Ejection fraction; $\mathrm{MI}=$ Myocardial Infarction; $\mathrm{NYHA}=\mathrm{New}$ York Heart Association; $\mathrm{OPCAB}=\mathrm{Off}-$ pump coronary artery bypass grafting; $\mathrm{PCI}=$ Percutaneous coronary intervention; $\mathrm{PVD}=$ Peripheral vascular disease.

Table-5.Postoperative outcomes(RIMA vs RA as $2^{\text {nd }}$-arterial graft)

\begin{tabular}{|c|c|c|c|c|c|c|}
\hline & $\begin{array}{l}\text { Before } \\
\text { matching } \\
\text { RIMA } \\
(\mathrm{n}=537)\end{array}$ & $\begin{array}{l}\text { Before } \\
\text { matching } \\
\text { RA }(n=180)\end{array}$ & $\begin{array}{l}\text { Before } \\
\text { matching } \\
\mathrm{P}^{\mathrm{a}}\end{array}$ & $\begin{array}{l}\text { After } \\
\text { matching } \\
\text { RIMA } \\
(\mathrm{n}=174)\end{array}$ & $\begin{array}{l}\text { After } \\
\text { matching } \\
\text { RA }(n=174)\end{array}$ & $\begin{array}{l}\text { After } \\
\text { matching } \\
\mathrm{P}^{\mathrm{b}}\end{array}$ \\
\hline $\begin{array}{l}\text { 30-day } \\
\text { mortality }\end{array}$ & $7(1.3)$ & $2(1.1)$ & 0.84 & $1(0.57)$ & $1(0.57)$ & 0.47 \\
\hline $\begin{array}{l}\text { 30-day } \\
\text { MACCE }\end{array}$ & $26(4.8)$ & $3(1.6)$ & 0.06 & $8(4.5)$ & $2(1.1)$ & 0.11 \\
\hline $\begin{array}{l}\text { Reoperation } \\
\text { due to } \\
\text { bleeding }\end{array}$ & $29(5.4)$ & $12(6.6)$ & 0.52 & $11(6.3)$ & $11(6.3)$ & 0.83 \\
\hline DSWI & $18(3.3)$ & $5(2.7)$ & 0.7 & $9(5.1)$ & $5(2.8)$ & 0.38 \\
\hline
\end{tabular}


Data are expressed as n(\%). a-Chi-square test ; b-McNemar test. DSWI=Deep sternal wound infection;MACCE $=$ Major advers cardiac and cerebral events.

References:

1. Loop FD, Lytle WD, Cosgrove DM, Stewart RW, Goormastic M, Williams GW et al. Influence of the internal-mammary-artery graft on 10-year survival and other cardiac events.N Engl J Med.1986;314:1-6.

2.Goldman S, Zadina K, Moritz T, Ovitt T, Sethi G, Copeland JG et al. Long-term patency of saphenous vein and left internal mammary artery grafts after coronary artery bypass surgery: results from a Department of Veterans Affairs Cooperative Study.J Am Coll Cardiol.2004;44:2149-56. 3.Sabik JF III, Lytle BW, Blackstone EH, Houghtaling PL, Cosgrove DM,. Comparison of saphenous vein and internal thoracic artery graft patency by coronary system.Ann Thorac Surg.2005;79:544-51; discussion 544-51.

4.Taggart DP, D'Amico R, Altman DG. Effect of arterial revascularisation on survival: a systematic review of studies comparing bilateral and single internal mammary arteries.Lancet (London, England). 2001;358:870875.

5.Lytle BW, Blackstone EH, Sabik JF, Houghtaling P, Loop FD, Cosgrove DM. The effect of bilateral internal thoracic artery grafting on survival during 20 postoperative years.Ann Thorac Surg.2004;78:20052012; discussion 2012-2014.

6.Benedetto U, Amrani M, Gaer J, Bahrami T, De Robertis F, Simon AR et al. The influence of bilateral internal mammary arteries on short- and long-term outcomes: A propensity score matching in accordance with current recommendations.J Thorac Cardiovasc Surg.2014;148:2699-705.

7.Gaudino M, Benedetto U, Fremes S, Biondi-Zoccai G, Sedrakyan A, Puskas JD et al. Radial-Artery or Saphenous-Vein Grafts in Coronary-Artery Bypass Surgery.N Engl J Med.2018;378:2069-2077.

8.Gaudino M, Lorusso R, Rahouma M, Abouarab A, Tam DY, Spadaccio C et al. Radial Artery Versus Right Internal Thoracic Artery Versus Saphenous Vein as the Second Conduit for Coronary Artery Bypass Surgery: A Network Meta-Analysis of Clinical Outcomes.J Am Heart Assoc.2019;22;8:e010839.doi:10.1161/JAHA.118.010839.

9. Tabata M, Grab JD, Khalpey Z, Edwards FH, O'Brien SM, Cohn LH et al. Prevalence and Variability of Internal Mammary Artery Graft Use in Contemporary Multivessel Coronary Artery Bypass Graft: analysis of the Society of Thoracic Surgeons National Cardiac Database.Circulation.2009;120:935-940.

10.Parasca CA, Head SJ, Mohr FW, Mack MJ, Morice MC, Holmes Jr DR et al.The impact of a second arterial graft on 5-year outcomes after coronary artery bypass grafting in the Synergy Between Percutaneous Coronary Intervention With TAXUS and Cardiac Surgery Trial and Registry. J Thorac Cardiovasc Surg. 2015;150:597-606.e2.

11. Taggart DP, Benedetto U, Gerry S, Altman DG, Gray AM, Lees B et al. Bilateral versus single internalthoracic artery grafts at 10 years.N Engl J Med.2019;380:437-446.

12.Taggart DP, Altman DG, Gray AM, Lees B, Nugara F, Yu LM et al. Randomized trial to compare bilateral vs. single internal mammary coronary artery bypass grafting: 1-year results of the Arterial Revascularisation Trial (ART).Eur Heart J.2010;31:2470-81.

13.Vandenbroucke JP, von Elm E, Altman DG, Gotzsche PC, Mulrow CD, Pocock SJ et al. Strengthening the Reporting of Observational Studies in Epidemiology (STROBE): explanation and elaboration.Int J Surg.2014;12:1500-24.

14.Thygesen K, Alpert JS, Jaffe AS, Chaitman BR, Bax JJ, Morrow DA et al. Fourth Universal Definition of Myocardial Infarction (2018) .J Am Coll Cardiol.2018;72:2231-2264.

15.Mangram AJ, Horan TC, Pearson ML, Silver LC, Jarvis WR. Guideline for Prevention of Surgical Site Infection, 1999. Centers for Disease Control and Prevention (CDC) Hospital Infection Control Practices 
Advisory Committee.Am J Infect Control.1999;27:97-132;quiz 133-134;discussion 96.

16.Head SJ, Mack MJ, Holmes DR Jr, Mohr FW, Morice MC, Serruys PW et al. Incidence, predictors and outcomes of incomplete revascularization after percutaneous coronary intervention and coronary artery bypass grafting: a subgroup analysis of 3-year SYNTAX data.Eur J Cardiothorac Surg.2012;41:535-41.

17.Lauer MS, Blackstone EH, Young JB, Topol EJ. Cause of death in clinical research: time for a reassessment?.J Am Coll Cardiol. 999;34:618-20.

18.Benedetto U, Head SJ, Angelini GD, Blackstone EH. Statistical pri-mer: propensity score matching and its alternatives.EurJ Cardiothorac Surg.2018;53:1112-1117.

19.Austin PC. Optimal caliper widths for propensity-score matching when estimating differences in means and differences in propor-tions in observational studies.Pharmaceut Statist.2011;10:150-161.

20.Austin PC. Statistical criteria for selecting the optimal number of untreated subjects matched to each treated subject when using many-to-one matching on the propensity score.Am J Epidemiol.2010;172:1092-7.

21.Chikwe J, Sun E, Hannan EL, Itagaki S, Lee T, Adams DH et al. Outcomes of Second Arterial Conduits in Patients Undergoing Multivessel Coronary Artery Bypass Graft Surgery.J Am Coll Cardiol.2019;74:22382248 .

22.Schwann TA, Hashim SW, Badour S, Obeid M, Engoren M, Tranbaugh RF et al. Equipoise between radial artery and right internal thoracic artery as the second arterial conduit in left internal thoracic artery-based coronary artery bypass graft surgery: a multi-institutional study.Eur J Cardiothorac Surg.2016;49:188-95.

23.Shi WY, Hayward PA, Tatoulis J, Rosalion A, Newcomb AE, Fuller JA et al. Are all forms of total arterial revascularization equal? A comparison of single versus bilateral internal thoracic artery grafting strategies.J Thorac Cardiovasc Surg.2015;150:1526-34.

24.Benedetto U, Caputo M, Gaudino M, Marisco R, Rajakaruna C, Bryan A et al. Right internal thoracic artery or radial artery? A propensity-matched comparison on the second-best arterial conduit.J Thorac Cardiovasc Surg.2017;153:79-88.e4. 25.Buxton BF, Hayward PA, Raman J, Moten SC, Rosalion A, Gordon I et al. Long-Term Results of the RAPCO Trials.Circulation.2020;142:1330-1338. 26.Benedetto U, Altman DG, Gerry S, Gray A, Lees B, Pawlaczyk R et al. Pedicled and skeletonized single and bilateral internal thoracic artery grafts and the incidence of sternal wound complications: Insights from the Arterial Revascularization Trial.J Thorac Cardiovasc Surg.2016;152:270-6.

27.Garcia S, Sandoval Y, Roukoz H, Adabag S, Canoniero M, Yannopoulos D et al. Outcomes after complete versus incomplete revascularization of patients with multivessel coronary artery disease: a meta-analysis of 89,883 patients enrolled in randomized clinical trials and observational studies.J Am Coll Cardiol.2013;62:1421-31. 


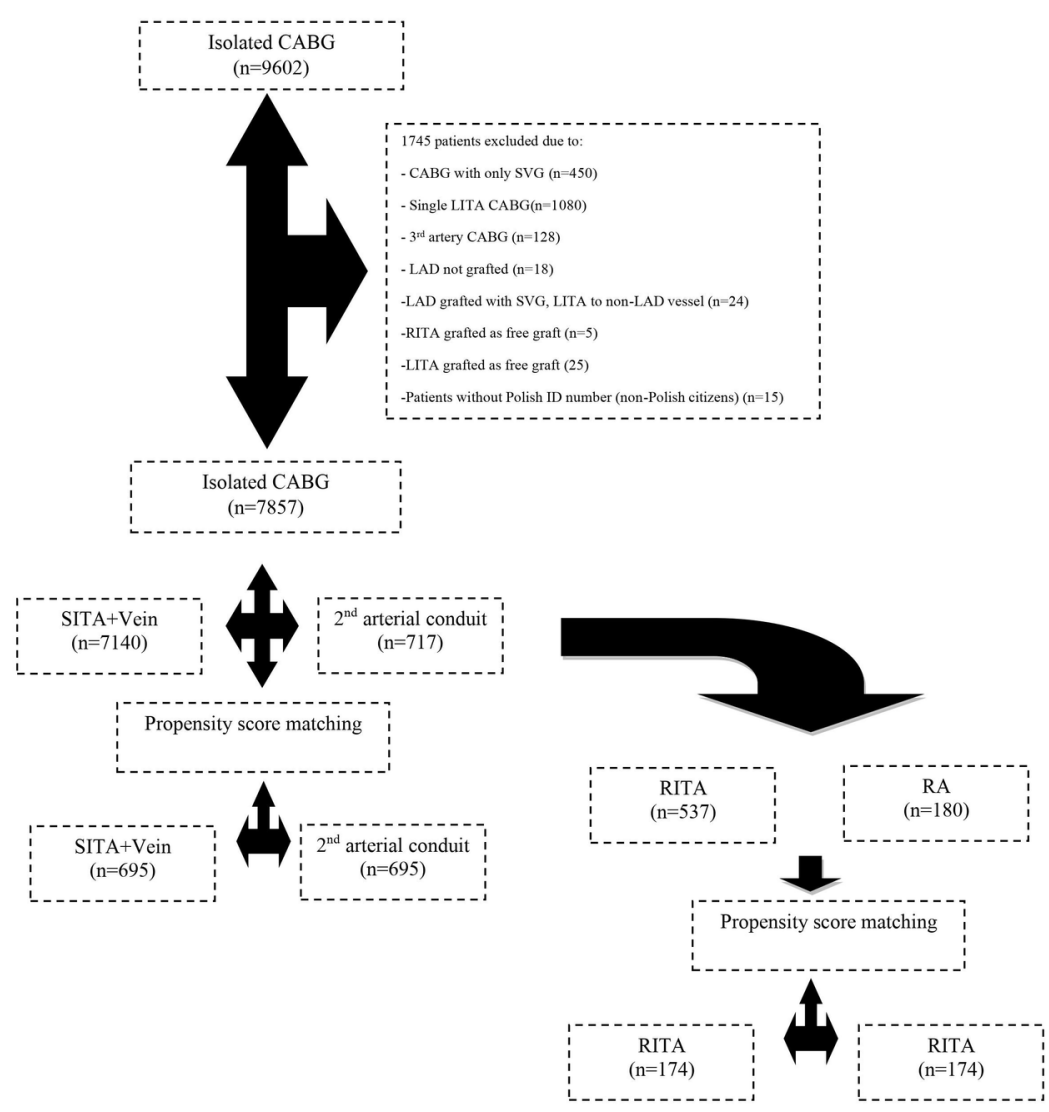


(A)

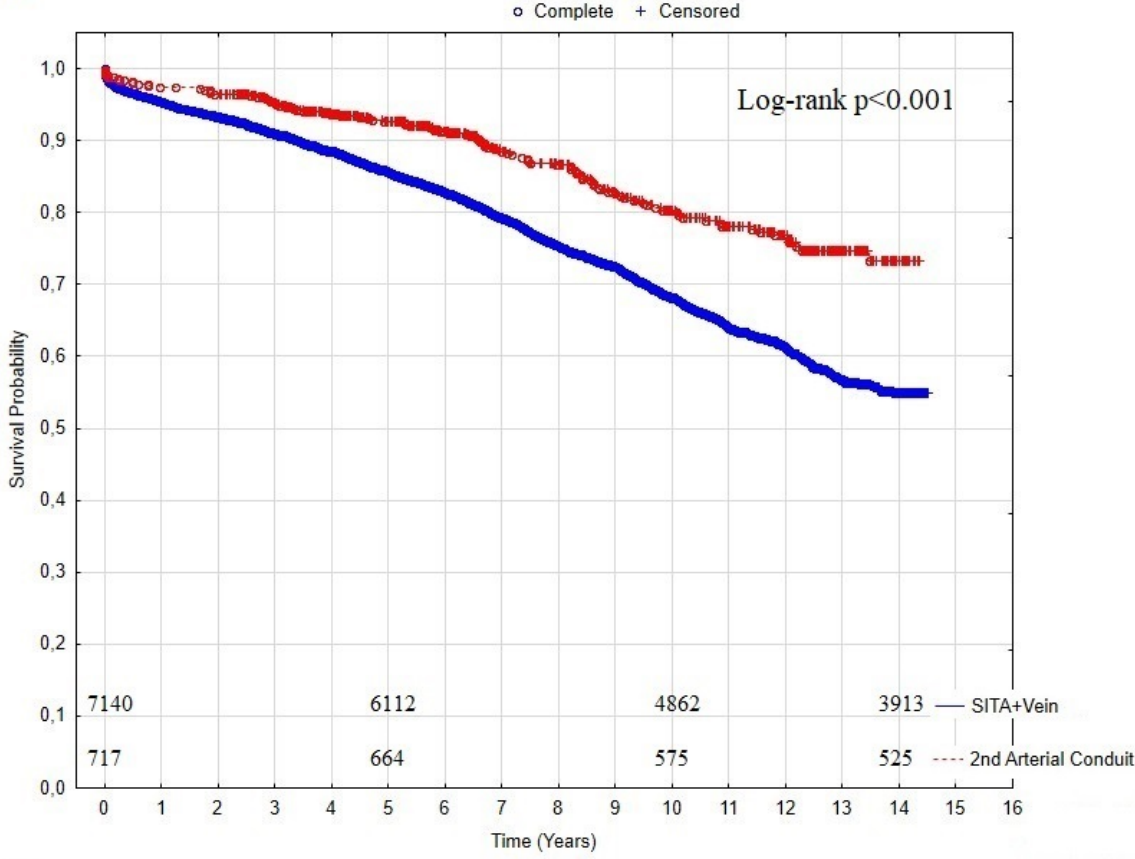

(B)

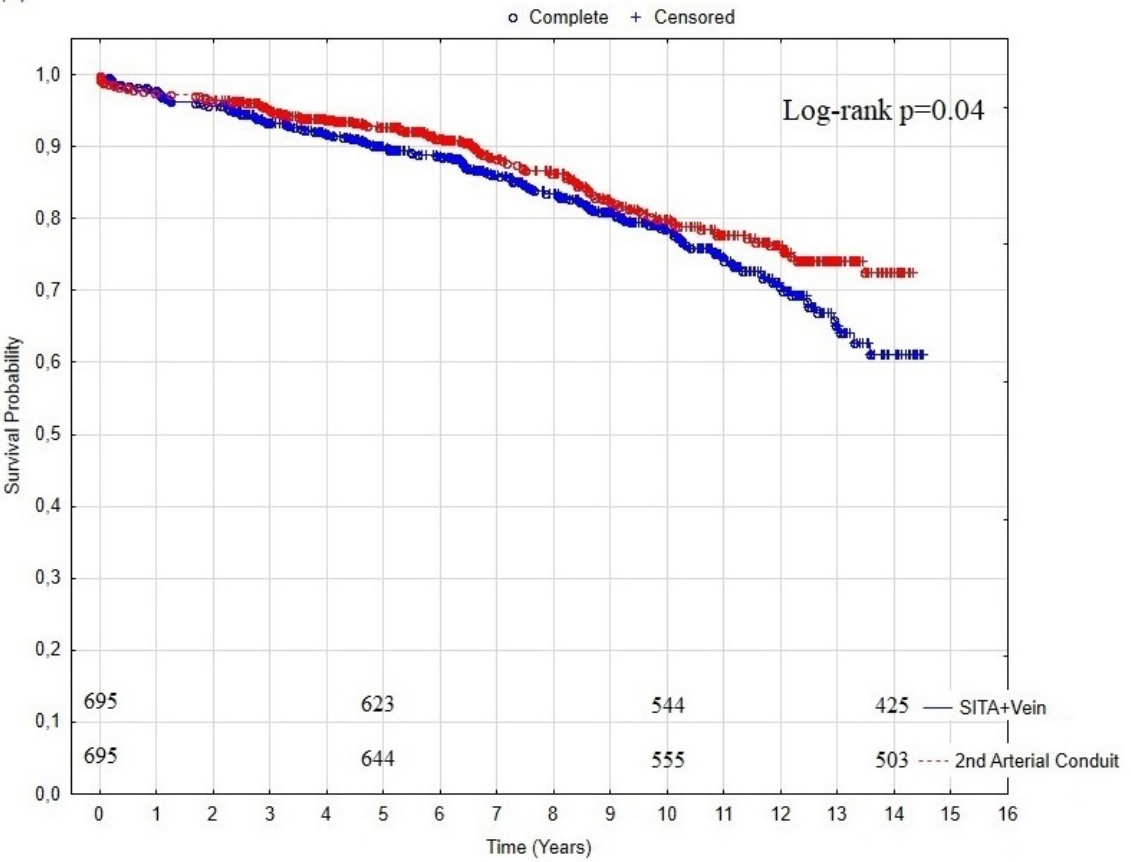


(A)

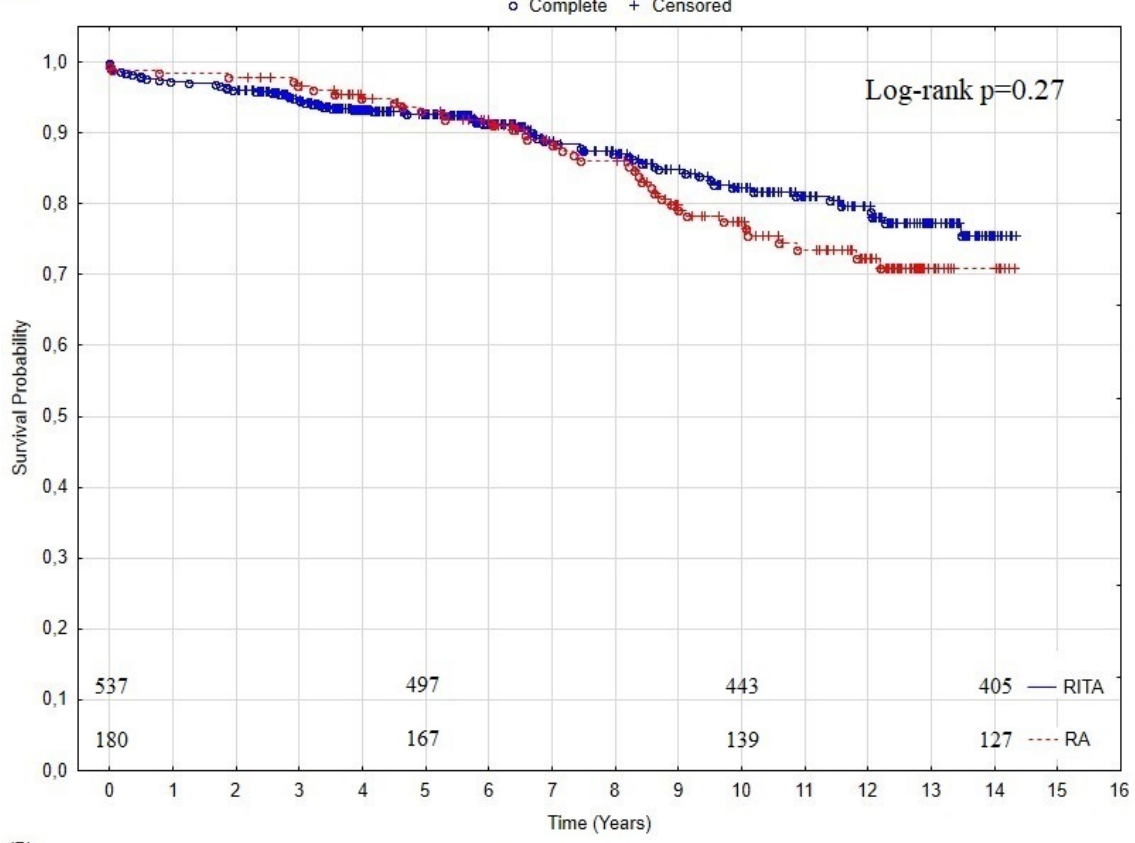

(B)

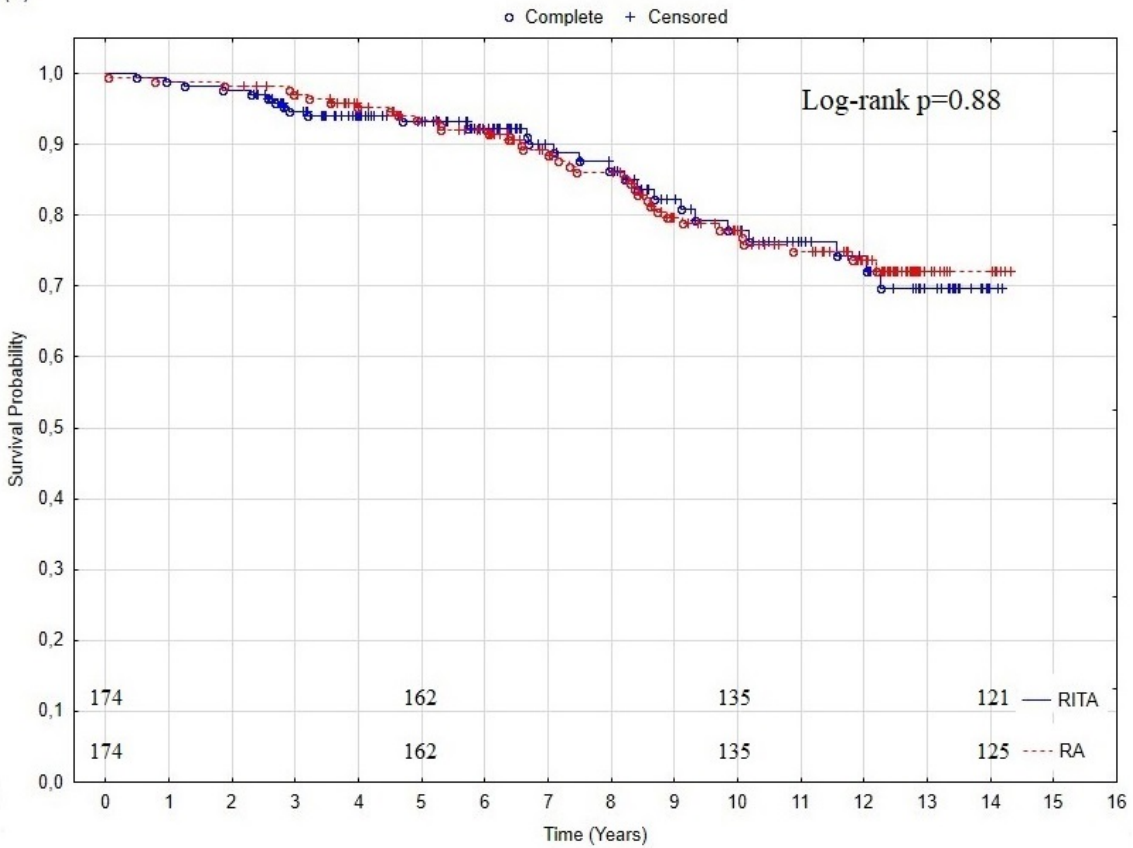

